\title{
PReS-FINAL-2171: Consensus: what agent to use when first-line vasodilators fail in Raynaud's phenomenon or digital ulcers secondary to rheumatic diseases in children?
}

\author{
M Katsicas*, M Gonzalez, R Russo, Consensus Working Group \\ From 20th Pediatric Rheumatology European Society (PReS) Congress \\ Ljubljana, Slovenia. 25-29 September 2013
}

\section{Introduction}

Juvenile Systemic Sclerosis (JSS) is characterized by Raynaud's phenomenon (RP) and digital ulcers (DU). Conventional therapy includes calcium channel blockers (CCB) A growing number of vasodilators is available for treatment of refractory patients but there is no clear evidence of the best option. To aid clinical decision-making, a consensus of expert was undertaken.

\section{Objectives}

To identify the best therapeutic options and define the sequence of $2^{\text {nd }}$ line vasodilators for RP and DU.

\section{Methods}

Steps in the process of consensus were: a) Identification of expert panel (EP) members, b) Identification of $2^{\text {nd }}$ line vasodilators $\mathrm{c}$ ) identification of outcome measures to define RP and DU improvement, d) systematic literature review; e) summary report of the latest scientific evidence f) expert consensus meeting; g) rating of the strength of evidence. RAND/UCLA appropriateness method was used for rating the medical decision: items were rated on a 9-point scale on each drug option. There were two scoring rounds: first: anonymous and independent rating of the appropriateness of vasodilators based on scientific evidence and best clinical judgment. Differences in scoring were discussed at a face-toface meeting, followed by a second rating round. Consensus was reached on appropriate/inappropriateness.

\section{Results}

The EP included 10 physicians from a tertiary center who are involved in the care of patients with JSS: 3 pediatric rheumatologists, 2 dermatologists, 1 pediatrician, 1 gastroenterologist, 1 nephrologist, 1 nutricionist, 1 pharmacologist, and a moderator. The EP identified 4 drugs for analysis: bosentan, iloprost, sildenafil, and trepostinil. Outcome measures were selected according to the literature references and EP judgment. RP improvement definition: $\geq 30 \%$ improvement according to the physician (in a visual analogue scale, VAS) and $\geq 30 \%$ improvement in at least 2 patient-related domains (pain or function). Patient domains were: a) number of episodes, b) pain in a VAS, c) function (impaired activity of daily living, VAS), d) RP episodes average duration (in minutes). DU improvement definition: a favorable change in all physician- and patient-related domains: patient's domains: a) pain (VAS) b) function (VAS); physician's domains: a) ulcer activity (VAS) b) horizontal and transverse DU diameter (in $\mathrm{mm}$ ). Systematic literature review was performed independently by $5 \mathrm{EP}$ members and guided by the moderator. All articles in English were eligible. Data bases included pubmed and Cochrane. The search strategy included all relevant terms: bosentan, iloprost, sildenafil, trepostinil, RP, DU, combined in different sets of keywords. The summary report of the scientific evidence included 25 articles. Ranking of papers according to the strength of evidence showed: 1a (1 paper), 1b (7), 2b (2), 3b (2), 4(8), 5(5). After second scoring round: $1^{\text {st }}$ appropriate indication Iloprost; $2^{\text {nd }}$ bosentan, $3^{\text {rd }}$ sildenafil; $4^{\text {th }}$ trepostinil. 


\section{Conclusion}

The EP reached a consensus on vasodilator drugs, providing direction for common dilemmas in the pharmacologic treatment of RP and DU in refractory patients.

\section{Disclosure of interest}

None declared.

Published: 5 December 2013

doi:10.1186/1546-0096-11-S2-P183

Cite this article as: Katsicas et al:: PReS-FINAL-2171: Consensus: what agent to use when first-line vasodilators fail in Raynaud's phenomenon or digital ulcers secondary to rheumatic diseases in children? Pediatric Rheumatology 2013 11(Suppl 2):P183.

Submit your next manuscript to BioMed Central and take full advantage of:

- Convenient online submission

- Thorough peer review

- No space constraints or color figure charges

- Immediate publication on acceptance

- Inclusion in PubMed, CAS, Scopus and Google Scholar

- Research which is freely available for redistribution

Submit your manuscript at www.biomedcentral.com/submit 